\title{
Does Liberal Prehospital and In-Hospital Tranexamic Acid Influence Outcome in Severely Injured Patients? A Prospective Cohort Study
}

\author{
Karlijn J. P. van Wessem ${ }^{1}$ (D) - Luke P. H. Leenen ${ }^{1}$
}

Accepted: 14 April 2021/Published online: 29 April 2021

(C) The Author(s) 2021

\begin{abstract}
Background Early hemorrhage control is important in trauma-related death prevention. Tranexamic acid (TXA) has shown to be beneficial in patients in hemorrhagic shock, although widespread adoption might result in incorrect TXA administration leading to increased morbidity and mortality.

Methods A 7-year prospective cohort study with consecutive trauma patients admitted to a Level-1 Trauma Center ICU was performed to investigate administration of both pre- and in-hospital TXA and its relation to morbidity and mortality. Indication for prehospital and in-hospital TXA administration was (suspicion of) hemorrhagic shock, and/ or systolic blood pressure (SBP) $\leq 90 \mathrm{mmHg}$. Demographics, data on physiology, resuscitation and outcomes were prospectively collected.

Results Four hundred and twenty-two patients (71\% males, median ISS 29, 95\% blunt injuries) were included. Even though TXA patients were more severely injured with more deranged physiology, no differences in outcome were noted. Overall, thrombo-embolic complication rate was $8 \%$. In half the patients, hemorrhagic shock was the indication for prehospital TXA, whereas 79\% of in-hospital TXA was given based on suspicion of hemorrhagic shock. Thirteen percent of patients with SBP $\leq 90 \mathrm{mmHg}$ in ED received no TXA at all. Based on SBP alone, $22 \%$ of prehospital TXA and 25\% of in-hospital TXA were justified.

Conclusions Despite being more severely injured, TXA patients had similar outcome compared to patients without TXA. Thrombo-embolic complication rate was low despite liberal use of both prehospital and in-hospital TXA. Caution should be exercised in selecting patients for TXA, although this might be challenging based on SBP alone in patients who do not yet show signs of deranged physiology on arrival in ED.
\end{abstract}

Supplementary Information The online version contains supplementary material available at https://doi.org/10.1007/s00268021-06143-y.

Karlijn J. P. van Wessem

kwessem@umcutrecht.nl

Luke P. H. Leenen

1.p.h.Leenen@umcutrecht.nl

1 Department of Trauma Surgery, University Medical Center Utrecht, Heidelberglaan 100, 3584 CX Utrecht, The Netherlands

\section{Background}

Early hemorrhage control and adequate blood product transfusion are important in trauma-related death prevention [1, 2]. Hemostatic resuscitation prevents ongoing blood loss, restores volume status and corrects coagulopathy development [3]. Tranexamic acid (TXA) is an anti-fibrinolytic agent that acts by inhibiting plasminogen activation and fibrinolysis and promotes the ability to sustain formed clots [4]. The Clinical Randomization of an Anti-fibrinolytic in Significant Hemorrhage 2 (CRASH-2) trial showed statistically significant improvement in the 
rates of both overall mortality and in hemorrhage-caused mortality as a result of early administration of TXA in adults who sustained an injury within $8 \mathrm{~h}$ and had either significant hemorrhage, hypotension or who were considered to be at risk of significant hemorrhage [5]. These results have led to widespread incorporation of TXA in damage control resuscitation with low thresholds to administer TXA, including in prehospital settings. However, concerns have been raised that indiscriminate widespread adoption might result in TXA administration in the wrong patients, leading to increased morbidity and mortality [6-9]. Data in the literature have been contradicting, however, with others reporting no significant differences or even decreased adverse effects [10-14]. At present, it remains unclear what the exact mechanism behind TXA is and how it has reduced mortality in CRASH-2 trial, since there was no reduction in packed red blood cells (PRBC) transfusion between patients who received TXA and the ones who did not [5]. Data are still lacking regarding which trauma patients might benefit most, optimal dosing and timing and potential complications in both prehospital and in-hospital setting [4, 15].

Since most studies only focused on either prehospital or in-hospital TXA administration, we conducted a prospective population-based cohort study in polytrauma patients to investigate the indication of both pre- and in-hospital TXA administration and its relation to morbidity and mortality. We hypothesized that neither prehospital nor inhospital TXA administration was related to increased morbidity or mortality.

\section{Materials and methods}

A 7-year prospective population-based cohort study (starting November 2013) was undertaken to investigate outcomes in severely injured patients admitted to the Intensive Care Unit (ICU) of a major (Level-1) trauma center (University Medical Center Utrecht, The Netherlands). Details of the hospital and catchment area were previously described [16]. All consecutive polytrauma patients who were admitted to the adult ICU were included. ICU admission could be either directly from the emergency department (ED) or postoperatively after urgent surgery. Patients with isolated traumatic brain injury (TBI), asphyxiation, drowning and burns were excluded, because of potential different physiologic response to severe trauma and a significantly different mortality and morbidity profile $[17,18]$. Isolated injury to the brain was defined as Abbreviated Injury Score (AIS) head $\geq 3$ and AIS $\leq 2$ in other regions.

All data were prospectively collected by both authors and included demographics, shock and resuscitation parameters. Administration of both crystalloid and blood products including packed red blood cells (PRBC), fresh frozen plasma (FFP) and platelets (PLT) was documented in the first $24 \mathrm{~h}$ after admission. Additionally, prehospital and in-hospital administration (in ED, OR, $\leq 8 \mathrm{~h}$ and $\leq 24 \mathrm{~h}$ ) of tranexamic acid (TXA) was recorded. Our trauma system's protocols, including prehospital protocols, recommend administering TXA within $3 \mathrm{~h}$ of injury for signs of the presence of impending hemorrhagic shock, hypotension (systolic blood pressure $\leq 90 \mathrm{mmHg}$ ) and/or clinical suspicion of major hemorrhage. Prehospital TXA dosage was $1 \mathrm{~g}$ bolus, in-hospital TXA dosage was also $1 \mathrm{~g}$ bolus, and $1 \mathrm{~g}$ infusion was repeated over $8 \mathrm{~h}$ at discretion of the treating surgeon and/or intensivist.

Denver MOF scores [19] and ARDS Berlin criteria [20] were registered daily up until 28 days or discharge from ICU. Primary outcome was the relation between TXA administration and potentially adverse outcomes such as mortality, thrombo-embolic complications (TEC), MODS, ARDS and infections.

Secondary outcome was potential difference between pre- and in-hospital TXA administration on outcome parameters.

All statistical analyses were performed using IBM SPSS Statistics, version 25.0 (Armonk, NY, USA). Results are presented as median and interquartile range (IQR). Kruskal-Wallis was used to test continuous variables for equality between TXA and patients without TXA, whereas Chi-square or Fisher's exact test was used to test categorical data. Variables with univariate statistical significance of less than 0.10 were included in a multivariate logistic regression analysis to identify independent risk factors for TXA administration and mortality and presented as odds ratios and $95 \%$ confidence intervals. Statistical significance was set at $p<0.05$.

\section{Results}

In this study, 422 patients ( $71 \%$ male) with a median age of 46 (28-62) years admitted to ICU were included. Ninetyfive percent of injuries were caused by a blunt mechanism, $50 \%$ was prehospitally intubated, and median ISS was 29 (22-36) with most severe injuries located in the brain (AIS head $3(1-4)$ ) and chest (AIS chest $3(2-4)$ ). One hundred and three patients (24\%) underwent an urgent laparotomy. Physiology, resuscitation and outcome data are presented in Table 1. In this cohort, 79 (19\%) patients died; $57(72 \%)$ of them died of traumatic brain injury (TBI), 7 (9\%) died of respiratory insufficiency, $4(5 \%)$ due to exsanguination, 3 (4\%) due to cardiac origin, $2(3 \%)$ due to MODS, $2(3 \%)$ due to sepsis, $1(1 \%)$ due to ARDS and $3(4 \%)$ due to miscellaneous causes. 
Table 1 Demographics, physiology and outcome

\begin{tabular}{|c|c|c|c|c|}
\hline & Total population $(n=422)$ & TXA $(n=280)$ & No TXA $(n=142)$ & $p$-Value \\
\hline Age (years) & $46(28-62)$ & $41(26-59)$ & $51(32-67)$ & $0.005^{*}$ \\
\hline Male gender & $298(71)$ & $202(72)$ & $96(68)$ & 0.37 \\
\hline Blunt MOI & $402(95)$ & $263(94)$ & $139(98)$ & 0.09 \\
\hline Prehospital intubation & $211(50)$ & $151(54)$ & $60(42)$ & $0.002 *$ \\
\hline Urgent laparotomy & $103(24)$ & $88(32)$ & $15(11)$ & $<0.001^{*}$ \\
\hline ISS & $29(22-36)$ & $29(23-38)$ & $29(21-34)$ & $0.003 *$ \\
\hline AIS head & $3(1-4)$ & $3(0-4)$ & $3(2-4)$ & 0.22 \\
\hline AIS face & $0(0-2)$ & $0(0-1)$ & $0(0-2)$ & 0.28 \\
\hline AIS chest & $3(2-4)$ & $3(2-4)$ & $3(2-3)$ & 0.27 \\
\hline AIS abdomen & $2(0-3)$ & $2(0-3)$ & $0(0-2)$ & $0.004 *$ \\
\hline AIS pelvis/extremities & $2(0-3)$ & $2(1-3)$ & $2(0-3)$ & $0.005^{*}$ \\
\hline AIS external & $0(0-1)$ & $0(0-1)$ & $0(0-1)$ & 0.31 \\
\hline SBP_ED (mmHg) & $120(98-140)$ & $117(91-135)$ & $130(105-144)$ & $<0.001^{*}$ \\
\hline $\mathrm{SBP} \leq 90 \mathrm{mmHg} \_$ED & $86(20)$ & $68(24)$ & $18(13)$ & $0.005^{*}$ \\
\hline Hb_ED (mmol/L) & $8.0(7.2-8.9)$ & $7.8(7.0-8.9)$ & $8.4(7.8-9.1)$ & $<0.001^{*}$ \\
\hline pH_ED & $7.31(7.25-7.36)$ & $7.30(7.23-7.36)$ & $7.33(7.28-7.39)$ & $<0.001^{*}$ \\
\hline PaC02_ED (mmHg) & $46(41-53)$ & $47(42-54)$ & $45(41-51)$ & 0.06 \\
\hline $\mathrm{BD} \_\mathrm{ED}(\mathrm{mmol} / \mathrm{L})$ & $3.0(0.0-6.0)$ & $4.0(1.0-8.0)$ & $2.0(0.5-5.0)$ & $<0.001 *$ \\
\hline PT_ED (sec) & $14.6(13.1-16.9)$ & $14.8(13.4-17.4)$ & $14.4(12.7-16.1)$ & $0.04 *$ \\
\hline \multicolumn{5}{|l|}{ Resuscitation parameters } \\
\hline Crystalloids $\leq 8 \mathrm{~h}(\mathrm{~L})$ & $4.5(2.3-6.2)$ & $5.1(3.0-7.0)$ & $2.9(1.4-5.0)$ & $<0.001 *$ \\
\hline $\mathrm{PRBC} \leq 8 \mathrm{~h}(\mathrm{U})$ & $1(0-4)$ & $2(0-6)$ & $0(0-0)$ & $<0.001^{*}$ \\
\hline $\mathrm{FFP} \leq 8 \mathrm{~h}(\mathrm{U})$ & $0(0-4)$ & $2(0-6)$ & $0(0-0)$ & $<0.001^{*}$ \\
\hline $\mathrm{PLT} \leq 8 \mathrm{~h}(\mathrm{U})^{\#}$ & $0(0-1)$ & $0(0-1)$ & $0(0-0)$ & $<0.001^{*}$ \\
\hline Crystalloids $\leq 24$ h $(\mathrm{L})$ & $7.3(4.8-10.1)$ & $8.2(6.0-11.0)$ & $5.5(3.7-7.9)$ & $<0.001^{*}$ \\
\hline $\mathrm{PRBC} \leq 24 \mathrm{~h}(\mathrm{U})$ & $1(0-5)$ & $3(0-7)$ & $0(0-1)$ & $<0.001^{*}$ \\
\hline $\mathrm{PRBC} \geq 10$ units $\leq 24 \mathrm{~h}$ & $44(10)$ & $42(15)$ & $2(1)$ & $<0.001 *$ \\
\hline $\mathrm{FFP} \leq 24 \mathrm{~h}(\mathrm{U})$ & $0(0-5)$ & $2(0-7)$ & $0(0-0)$ & $<0.001^{*}$ \\
\hline $\mathrm{PLT} \leq 24 \mathrm{~h}(\mathrm{U})^{\#}$ & $0(0-1)$ & $0(0-1)$ & $0(0-0)$ & $<0.001^{*}$ \\
\hline \multicolumn{5}{|l|}{ Outcome parameters } \\
\hline Ventilator days & $6(2-11)$ & $5(2-11)$ & $6(2-11)$ & 0.68 \\
\hline ICU LOS (days) & $7(3-13)$ & $7(3-13)$ & $7(3-13)$ & 0.86 \\
\hline H-LOS (days) & $20(11-31)$ & $21(10-33)$ & $18(11-29)$ & 0.40 \\
\hline MODS & $66(16)$ & $42(15)$ & $24(17)$ & 0.67 \\
\hline ARDS & $16(4)$ & $7(3)$ & $9(6)$ & 0.06 \\
\hline Infectious complications & $179(42)$ & $119(43)$ & $60(42)$ & 1.0 \\
\hline Thrombo-embolic complications & $32(8)$ & $25(9)$ & $7(5)$ & 0.18 \\
\hline Mortality & 79 (19) & $56(20)$ & $23(16)$ & 0.36 \\
\hline
\end{tabular}

Data are expressed in median (IQR) or absolute numbers (\%)

$M O I$ Mechanism of Injury, ISS injury severity score, $A I S$ abbreviated injury scale, ED emergency department, $S B P$ systolic blood pressure, $H b$ hemoglobin, $\mathrm{PaCO} 2$ partial pressure of carbon dioxide in arterial blood, $B D$ base deficit, $P T$ prothrombin time, $P R B C$ packed red blood cells, $I C U$ intensive care unit, $L O S$ length of stay, $H-L O S$ hospital length of stay, MODS multiple organ dysfunction syndrome, ARDS adult respiratory distress syndrome

* Statistically significant

${ }^{\#} 1$ unit of platelets contains five donors 
Sixty-six percent of patients received TXA at any point in time. During the 7-year study period, prehospital TXA administration increased ( $p=0.005$, Figure S1A), whereas in-hospital TXA administration did not change over time ( $p=0.14$, Figure S1B). Patients who received TXA were younger, more severely injured, with lower SBP and hemoglobin $(\mathrm{Hb})$ in ED. Further, they were more acidotic and coagulopathic, underwent more often an urgent laparotomy and received more crystalloids and blood products both $\leq 8$ and $\leq 24 \mathrm{~h}$ than patients who did not receive TXA. There was, however, no difference in outcome between TXA and no-TXA patients (Table 1). There was also no difference in outcome between patients with $\mathrm{SBP} \leq 90 \mathrm{mmHg}$ who received TXA and those who did not.

\section{Subanalysis of patients who received prehospital TXA compared to patients who did not}

Forty-nine percent $(n=207)$ of patients received prehospital TXA, whereas 51\% $(n=215)$ did not (Fig. 1). Median time from call to dispatch to ED (prehospital time) was 1:00 h (0:55-1:08), so all prehospital TXA was administered within $1 \mathrm{~h}$ after injury. Patients who received prehospital TXA were younger, slightly more severely injured and more often prehospitally intubated. Further, prehospital TXA patients had lower $\mathrm{Hb}$ and were more acidotic in ED with higher $\mathrm{PaCO} 2$. They received more crystalloids and $\mathrm{PRBC} \leq 8$ and $\leq 24 \mathrm{~h}$. There was no difference in outcome (Table 2). All four patients (50\% had SBP $\leq 90 \mathrm{mmHg}$ ) who later died of hemorrhage did not receive prehospital TXA. However, they all did receive TXA in OR.

\section{Subanalysis of patients who received in-hospital TXA compared to patients who did not}

Two hundred and seventy-six $(65 \%)$ patients received inhospital TXA, whereas 146 did not (Fig. 1). Seventy-four percent had already received prehospital TXA. Patients who received in-hospital TXA were younger, more severely injured with lower SBP and $\mathrm{Hb}$, more acidotic and coagulopathic in ED than patients who did not receive inhospital TXA. Further, they underwent more often urgent laparotomies and received more crystalloids and blood products $\leq 8$ and $\leq 24 \mathrm{~h}$. Again, there was no difference in outcome (Table 3 ).

Median time to TXA was 1:02 h (0:58-1:20). The time frame within TXA was administered is shown in Fig. 2. Ninety-three percent of patients who had TXA received it early $(<3 \mathrm{~h})$ after injury. There was no difference in outcome in patients who had early TXA compared to late TXA ( $\geq 3 \mathrm{~h}$ ) (Table S1).

There was no significant difference in TXA dosage in TXA patients who received early TXA compared to late TXA (1 g (1-2) vs. $1 \mathrm{~g}(1-1), p=0.16)$. There was also no difference in TXA dosage between patients who developed TEC and those who did not $(1 \mathrm{~g}(1-2)$ vs. $1 \mathrm{~g}(1-1)$, respectively, $p=0.20$ ).

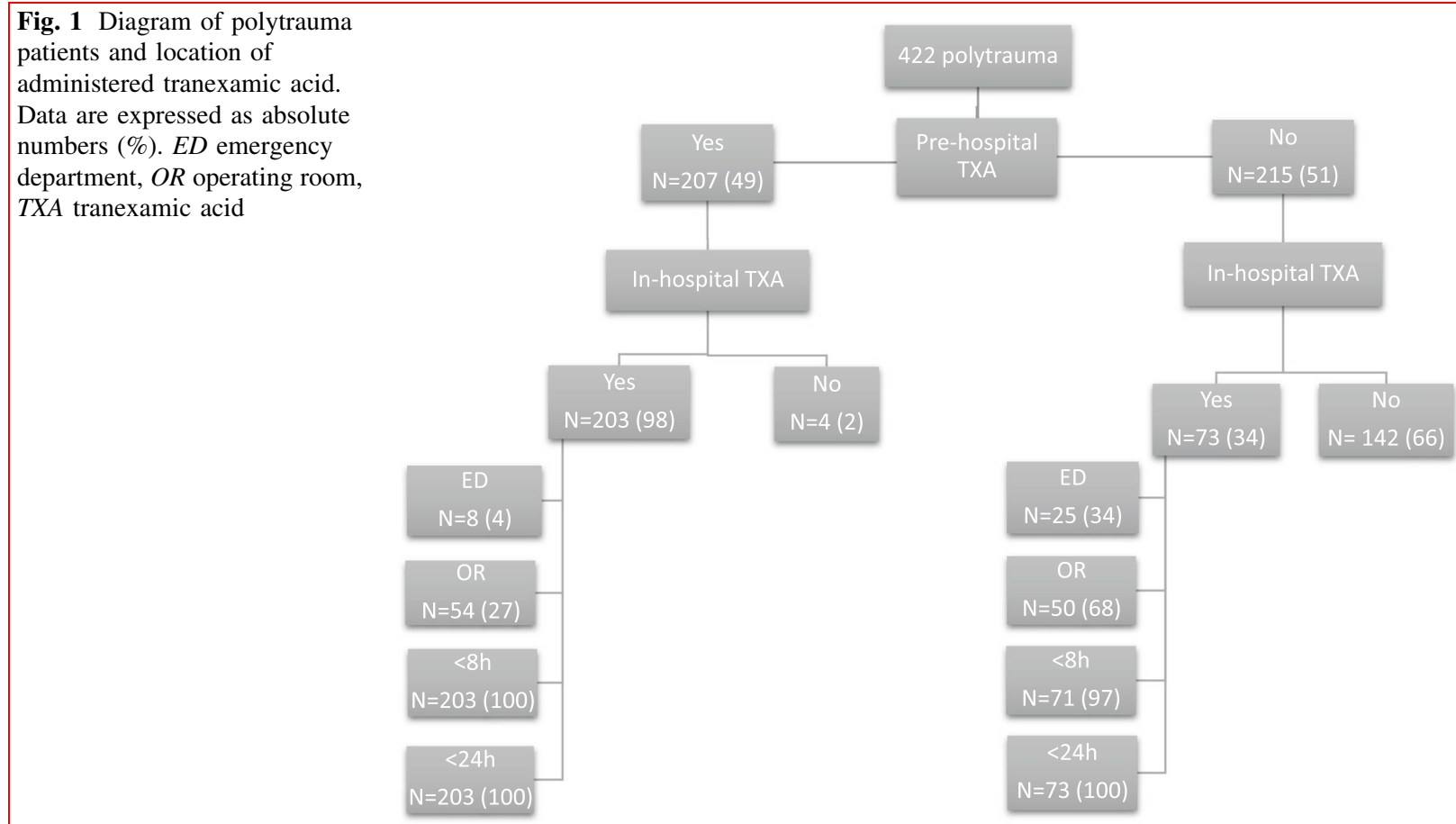


Table 2 Comparison of patients who received prehospital tranexamic acid (TXA) and patients who did not

\begin{tabular}{|c|c|c|c|}
\hline Demographics $N=422$ & Prehospital TXA $(n=207)$ & No prehospital TXA $(n=215)$ & $p$-Value \\
\hline Age (years) & $40(26-57)$ & $49(31-66)$ & $0.004 *$ \\
\hline Male gender & $152(73)$ & $146(68)$ & 0.24 \\
\hline Blunt MOI & $195(94)$ & $207(96)$ & 0.36 \\
\hline Prehospital intubation & $134(65)$ & $77(36)$ & $<0.001$ \\
\hline Urgent laparotomy & $52(25)$ & $51(24)$ & 0.82 \\
\hline ISS & $29(22-38)$ & $29(22-35)$ & $0.01^{*}$ \\
\hline AIS head & $3(1-4)$ & $3(1-4)$ & 0.68 \\
\hline AIS face & $0(0-2)$ & $0(0-1)$ & 0.43 \\
\hline AIS chest & $3(2-4)$ & $3(2-4)$ & 0.26 \\
\hline AIS abdomen & $2(0-3)$ & $0(0-3)$ & 0.76 \\
\hline AIS pelvis/extremities & $2(1-3)$ & $2(0-3)$ & 0.17 \\
\hline AIS external & $0(0-1)$ & $0(0-1)$ & 0.84 \\
\hline SBP_ED (mmHg) & $120(95-136)$ & $120(100-140)$ & 0.22 \\
\hline $\mathrm{SBP} \leq 90 \mathrm{mmHg}$ _ED & $45(22)$ & $41(19)$ & 0.55 \\
\hline Hb_ED (mmol/L) & $7.8(7.0-8.9)$ & $8.2(7.4-9.1)$ & $0.008 *$ \\
\hline pH_ED & $7.29(7.23-7.35)$ & $7.32(7.27-7.38)$ & $0.001 *$ \\
\hline PaCO2_ED (mmHg) & $48(42-54)$ & $45(34-51)$ & $<0.001 *$ \\
\hline BD_ED (mmol/L) & $3.0(1.0-7.5)$ & $3.0(0.0-6.0)$ & 0.22 \\
\hline PT_ED (sec) & $14.7(13.1-17.3)$ & $14.5(13.2-16.8)$ & 0.76 \\
\hline \multicolumn{4}{|l|}{ Resuscitation parameters } \\
\hline Crystalloids $\leq 8 \mathrm{~h}(\mathrm{~L})$ & $4.9(2.7-6.8)$ & $3.8(1.9-5.9)$ & $0.001 *$ \\
\hline $\mathrm{PRBC} \leq 8 \mathrm{~h}(\mathrm{U})$ & $2(0-5)$ & $0(0-4)$ & $0.003 *$ \\
\hline $\mathrm{FFP} \leq 8 \mathrm{~h}(\mathrm{U})$ & $2(0-5)$ & $0(0-0)$ & 0.14 \\
\hline $\mathrm{PLT} \leq 8 \mathrm{~h}(\mathrm{U})^{\#}$ & $0(0-4)$ & $0(0-4)$ & 0.28 \\
\hline Crystalloids $\leq 24 \mathrm{~h}(\mathrm{~L})$ & $7.8(5.6-10.5)$ & $6.7(4.4-9.5)$ & $0.002 *$ \\
\hline $\mathrm{PRBC} \leq 24 \mathrm{~h}(\mathrm{U})$ & $2(0-6)$ & $0(0-4)$ & $0.002 *$ \\
\hline PRBC $\geq 10$ units $\leq 24 \mathrm{~h}$ & $28(14)$ & $16(8)$ & 0.06 \\
\hline $\mathrm{FFP} \leq 24 \mathrm{~h}(\mathrm{U})$ & $2(0-6)$ & $0(0-4)$ & 0.17 \\
\hline $\mathrm{PLT} \leq 24 \mathrm{~h}(\mathrm{U})^{\#}$ & $0(0-1)$ & $0(0-1)$ & 0.21 \\
\hline \multicolumn{4}{|l|}{ Outcome parameters } \\
\hline Ventilator days & $5(2-10)$ & $6(2-11)$ & 0.40 \\
\hline ICU LOS (days) & $7(3-12)$ & $7(3-14)$ & 0.29 \\
\hline H-LOS (days) & $20(10-31)$ & $20(11-32)$ & 0.87 \\
\hline MODS & $28(14)$ & $38(18)$ & 0.28 \\
\hline ARDS & $4(2)$ & $12(6)$ & 0.07 \\
\hline Infectious complications & $85(41)$ & $94(44)$ & 0.56 \\
\hline Thrombo-embolic complications & $12(6)$ & $20(9)$ & 0.20 \\
\hline Mortality & $39(19)$ & $40(19)$ & 1.0 \\
\hline
\end{tabular}

Data are expressed in median (IQR) or absolute numbers (\%)

$M O I$ Mechanism of injury, ISS injury severity score, $A I S$ abbreviated injury scale, $E D$ emergency department, $S B P$ systolic blood pressure, $H b$ hemoglobin, $\mathrm{PaCO} 2$ partial pressure of carbon dioxide in arterial blood, $B D$ base deficit, $P T$ prothrombin time, $P R B C$ packed red blood cells, $I C U$ intensive care unit, LOS length of stay, $H$-LOS hospital length of stay, MODS multiple organ dysfunction syndrome, ARDS adult respiratory distress syndrome

*Statistically significant

\#1 unit of platelets contains five donors 
Table 3 Comparison of patients who received in-hospital TXA and patients who did not

\begin{tabular}{|c|c|c|c|}
\hline Demographics $N=422$ & In-hospital TXA $(n=276)$ & No in-hospital TXA $(n=146)$ & $p$-Value \\
\hline Age (years) & $42(26-59)$ & $51(32-67)$ & $0.01 *$ \\
\hline Male gender & $200(72)$ & $98(67)$ & 0.26 \\
\hline Blunt MOI & $259(94)$ & $143(98)$ & 0.09 \\
\hline Prehospital intubation & $149(54)$ & $62(43)$ & $0.001 *$ \\
\hline Urgent laparotomy & $88(32)$ & $15(10)$ & $<0.001 *$ \\
\hline ISS & $29(22-38)$ & $29(22-34)$ & $0.005^{*}$ \\
\hline AIS head & $3(0-4)$ & $3(2-4)$ & $0.02 *$ \\
\hline AIS face & $0(0-1)$ & $0(0-2)$ & 0.58 \\
\hline AIS chest & $3(2-4)$ & $3(2-3)$ & 0.82 \\
\hline AIS abdomen & $2(0-3)$ & $0(0-2)$ & $<0.001 *$ \\
\hline AIS pelvis/extremities & $2(1-3)$ & $2(0-3)$ & $<0.001^{*}$ \\
\hline AIS external & $0(0-1)$ & $0(0-1)$ & 0.96 \\
\hline SBP_ED (mmHg) & $117(91-135)$ & $130(105-144)$ & $<0.001 *$ \\
\hline $\mathrm{SBP} \leq 90 \mathrm{mmHg}$ ED & $68(25)$ & $18(12)$ & $0.002 *$ \\
\hline Hb_ED (mmol/L) & $7.8(7.0-8.9)$ & $8.4(7.8-9.1)$ & $<0.001^{*}$ \\
\hline pH_ED & $7.30(7.23-7.36)$ & $7.33(7.28-7.39)$ & $<0.001^{*}$ \\
\hline $\mathrm{PaCO} 2(\mathrm{mmHg})$ & $47(41-54)$ & $45(41-51)$ & 0.12 \\
\hline $\mathrm{BD} \_\mathrm{ED}(\mathrm{mmol} / \mathrm{L})$ & $4.0(1.0-8.0)$ & $2.0(1.0-5.0)$ & $<0.001^{*}$ \\
\hline PT_ED (sec) & $14.9(13.3-17.5)$ & $14.3(12.7-16.0)$ & $0.02 *$ \\
\hline \multicolumn{4}{|l|}{ Resuscitation parameters } \\
\hline Crystalloids $\leq 8 \mathrm{~h}(\mathrm{~L})$ & $5.2(3.1-7.1)$ & $2.9(1.4-5.0)$ & $<0.001^{*}$ \\
\hline $\mathrm{PRBC} \leq 8 \mathrm{~h}(\mathrm{U})$ & $2(0-7)$ & $0(0-0)$ & $<0.001^{*}$ \\
\hline $\mathrm{FFP} \leq 8 \mathrm{~h}(\mathrm{U})$ & $2(0-6)$ & $0(0-0)$ & $<0.001^{*}$ \\
\hline $\mathrm{PLT} \leq 8 \mathrm{~h}(\mathrm{U})^{\#}$ & $0(0-1)$ & $0(0-0)$ & $<0.001 *$ \\
\hline Crystalloids $\leq 24 \mathrm{~h}(\mathrm{~L})$ & $8.2(6.1-11.0)$ & $5.5(3.7-7.9)$ & $<0.001^{*}$ \\
\hline $\mathrm{PRBC} \leq 24 \mathrm{~h}(\mathrm{U})$ & $3(0-7)$ & $0(0-1)$ & $<0.001^{*}$ \\
\hline $\mathrm{PRBC} \geq 10$ units $\leq 24 \mathrm{~h}$ & $42(15)$ & $2(1)$ & $<0.001^{*}$ \\
\hline $\mathrm{FFP} \leq 24 \mathrm{~h}(\mathrm{U})$ & $2(0-7)$ & $0(0-0)$ & $<0.001 *$ \\
\hline $\mathrm{PLT} \leq 24 \mathrm{~h}(\mathrm{U})^{\#}$ & $0(0-1)$ & $0(0-0)$ & $<0.001 *$ \\
\hline \multicolumn{4}{|l|}{ Outcome parameters } \\
\hline Ventilator days & $5(2-11)$ & $6(2-10)$ & 0.79 \\
\hline ICU LOS (days) & $7(3-13)$ & $7(3-13)$ & 0.81 \\
\hline H-LOS (days) & $21(10-33)$ & $18(11-29)$ & 0.54 \\
\hline MODS & $42(15)$ & $24(16)$ & 0.78 \\
\hline ARDS & $7(3)$ & $9(6)$ & 0.10 \\
\hline Infectious complications & $117(42)$ & $62(42)$ & 1.0 \\
\hline Thrombo-embolic complications & $25(9)$ & $7(5)$ & 0.13 \\
\hline Mortality & $55(20)$ & $24(16)$ & 0.43 \\
\hline
\end{tabular}

Data are expressed in median (IQR) or absolute numbers (\%)

$M O I$ Mechanism of injury, ISS injury severity score, $A I S$ abbreviated injury scale, $E D$ emergency department, $S B P$ systolic blood pressure, $H b$ hemoglobin, $\mathrm{PaCO} 2$ partial pressure of carbon dioxide in arterial blood, $B D$ base deficit, $P T$ prothrombin time, $P R B C$ packed red blood cells, $I C U$ intensive care unit, $L O S$ length of stay, $H-L O S$ hospital length of stay, MODS multiple organ dysfunction syndrome, ARDS adult respiratory distress syndrome

* Statistically significant

\# 1 unit of platelets contains five donors 


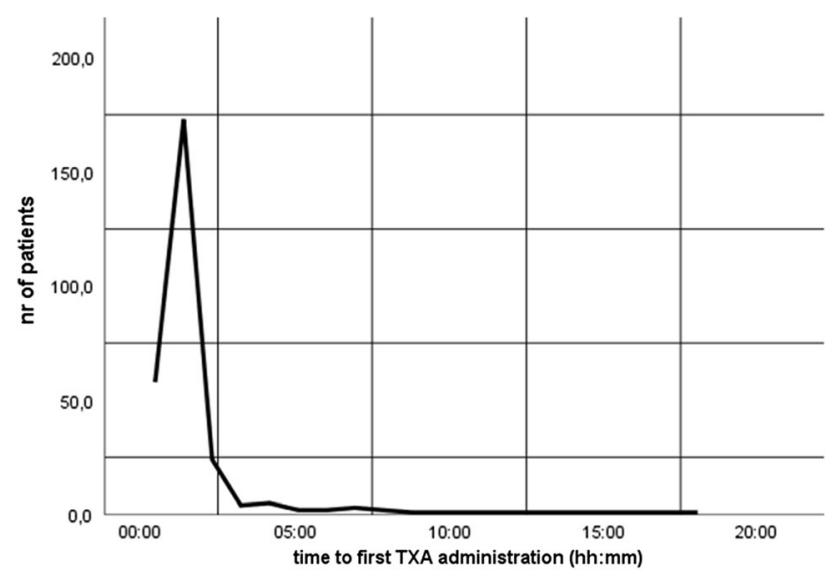

Fig. 2 Time to first tranexamic acid (TXA) administration

Fifty-two percent (45/86) of patients who received prehospital TXA had SBP $\leq 90 \mathrm{mmHg}$ compared to $79 \%$ (68/ 86) of patients who received in-hospital TXA (Table 4). Seventy-eight percent $(162 / 207)$ of patients received prehospital TXA despite SBP > $90 \mathrm{mmHg}$ in ED, and 75\% (208/276) of patients received in-hospital TXA despite SBP $>90 \mathrm{mmHg}$ in ED. Further, 32\% (23/73) of patients who had in-hospital TXA had unjustified not received prehospital TXA, and 13\% (18/142) of patients who had $\mathrm{SBP} \leq 90 \mathrm{mmHg}$ in ED received no TXA at all. Based on systolic blood pressure alone, 22\% (45/207) of prehospital TXA and 25\% (68/276) of in-hospital TXA were justified (Table 4).

In multivariate analysis, age, hemoglobin, $\mathrm{PaCO} 2$ and $\mathrm{pH}$ in ED were independent predictors for TXA administration. Age, ISS and base deficit in ED were independent predictors for mortality. TXA, however, was not related to death (Tables 5, 6).

\section{Discussion}

In this cohort of polytrauma patients, there was no difference in outcome between patients who received TXA and those who did not, even though TXA patients were more severely injured with more deranged physiology.
Subanalysis of prehospital and in-hospital TXA administration also revealed no difference in outcome. Based on systolic blood pressure alone $(\mathrm{SBP} \leq 90 \mathrm{mmHg})$, large numbers of unjustified prehospital and in-hospital TXA administration were found. However, these large numbers could be slightly overestimated since no data on prehospital SBP were collected and the first collected SBP for this study was in ED. It is possible that prehospital SBP could have been higher and decreased during transport. Moreover, since the original inclusion to administer TXA was a rather vague and subjective description of "signs of the presence of impending hemorrhagic shock and/or clinical suspicion of major hemorrhage," in this study SBP $\leq 90$ mmHg was used as most objective measurement of hemorrhagic shock to be able to calculate whether TXA administration was justified. This strict inclusion of SBP $\leq 90 \mathrm{mmHg}$ might label TXA as "unjustified" in some patients with normal SBP even though they were in imminent shock. Especially in prehospital settings, it could be difficult to diagnose early signs of hemorrhagic shock, and a "better safe than sorry" attitude is often adopted. Another reason for TXA administration in patients without hypotension might be explained by a previously described phenomenon in which severely injured patients in smaller service areas with short transport times do not have deranged physiologic parameters on arrival in ED. These patients did not have the time to deteriorate, because they were in the hospital before blood pressure, BD and hemoglobin will change distinctly [21, 22].

This liberal approach of prehospital TXA administration even increased over time during the 7-year study and has recently also been described by Kheirbek et al. Despite large numbers of unjustified TXA use, they also did not demonstrate difference in TEC [23].

In addition to the rationale of unjustified TXA administration, it is also intriguing why patients with signs of shock did not receive TXA. A few of these patients had shock based on other causes than hemorrhage such as neurogenic shock based on high spinal cord lesion. Four patients $(5 \%)$ who died due to hemorrhagic shock did not receive prehospital TXA, nor in ED. They all did receive TXA in OR. It could be debated that time was so critical in these exsanguinating patients that there was simply no time

Table 4 Relation between systolic blood pressure (SBP) $\leq 90 \mathrm{mmHg}$ in ED and TXA administration

\begin{tabular}{llllll}
\hline & Prehospital TXA & No prehospital TXA & In-hospital TXA & No in-hospital TXA & Total no. of patients \\
\hline SBP_ED $\leq 90 \mathrm{mmHg}$ & 45 & 41 & 68 & 18 & 86 \\
SBP_ED $>90 \mathrm{mmHg}$ & 162 & 174 & 208 & 128 & 336 \\
Total no. of patients & 207 & 215 & 276 & 146 & 422 \\
\hline
\end{tabular}

$S B P$ systolic blood pressure, ED emergency department, TXA tranexamic acid 
Table 5 Independent predictors for TXA administration

\begin{tabular}{llllr}
\hline Variables in the equation & B Coefficient & $p$-Value & Odds ratio & \multicolumn{2}{c}{$95 \%$ C.I } & Lower \\
\cline { 3 - 5 } & & & & 0.969 \\
\hline Age & & 0.001 & 0.981 & 0.992 \\
ISS & -0.019 & 0.306 & 1.011 & 0.990 \\
SBP_ED & 0.011 & 0.893 & 0.999 & 0.991 \\
Hb_ED & -0.001 & 0.000 & 0.960 & 0.939 \\
BD_ED & -0.041 & 0.099 & 1.017 & 0.997 \\
PT_ED & 0.017 & 0.573 & 0.999 & 0.995 \\
PaCO2_ED & -0.001 & 0.034 & 0.908 & 0.831 \\
pH_ED & -0.096 & 0.023 & 0.853 & 0.037 \\
Constant & -0.159 & 0.019 & $3.989 \mathrm{E}+54$ & 0.993 \\
\hline
\end{tabular}

Table 6 Independent predictors for mortality

\begin{tabular}{llllr}
\hline Variables in the Equation & B Coefficient & P-Value & Odds Ratio & \multicolumn{2}{c}{$95 \%$ C.I } & Lower \\
\cline { 4 - 5 } & & & Upper \\
\hline Age & & 0.046 & 1.047 & 1.065 \\
Laparotomy & -0.156 & 0.695 & 0.856 & 1.030 \\
ISS & 0.050 & 0.000 & 1.052 & 0.393 \\
SBP_ED & 0.008 & 0.095 & 1.008 & 1.025 \\
Hb_ED & -0.006 & 0.609 & 0.994 & 0.999 \\
BD_ED & -0.016 & 0.000 & 0.984 & 0.971 \\
Thrombo-embolic complications & -0.453 & 0.560 & 0.636 & 0.978 \\
TXA & -0.096 & 0.773 & 0.908 & 0.139 \\
Constant & -6.625 & 0.000 & 0.001 & 0.990 \\
\hline
\end{tabular}

ISS Injury severity score, $S B P$ systolic blood pressure, $B D$ base deficit, $E D$ emergency department, $H b$ hemoglobin, $P T$ prothrombin time, $\mathrm{PaCO} 2$ partial pressure of carbon dioxide, TXA tranexamic acid

to administer TXA prehospitally nor in ED. This was contradicted by reviewing both prehospital transport times and time from ED to OR in these patients, and there was no difference compared to other patients who needed urgent surgery. It remains unclear whether these patients would have survived if they had received TXA earlier.

Almost all patients who received TXA for the first time had it within the recommended $3 \mathrm{~h}$ after injury. There was no difference in dosage between patients who had early TXA and those who had late TXA nor was there any difference in outcome suggesting that both dosage and timing of TXA did not influence outcome.

Our data are in line with several other reports in the literature suggesting that TXA in a polytrauma population was not associated with increased TEC and mortality even if it was administered liberally [10-13]. However, current data are in contrast to other studies that demonstrated increased mortality after TXA [6-9]. A possible explanation for these seemingly contradicting data was proposed by Moore et al. suggesting that outcome after TXA might be related to fibrinolytic state of the patient with least expected benefit from TXA in patients with physiological fibrinolysis [9, 24]. In our hospital, viscoelastic tests are not routinely used in trauma. However, in a previous study thromboelastography in severely injured patients (who were part of the same cohort used in this study) showed no abnormalities [25]; therefore, it could be assumed that the patients in this study had physiological levels of fibrinolysis. Nevertheless, there was no difference in mortality between patients who received TXA and patients who did not in this study.

Despite being more severely injured TXA patients had no difference in outcome suggesting that TXA has ameliorated outcome. This should be concluded with caution; First of all, even if only patients with $\mathrm{SBP} \leq 90 \mathrm{mmHg}$ in ED were analyzed, there was no difference in morbidity 
and mortality between patients with and without TXA. Further, the numbers of exsanguinating patients were very low since only four patients died of hemorrhage. Additionally, it remains to be seen whether TXA is truly advantageous in settings with small service areas with short transport times and with the immediate availability of blood products and operating room to control hemorrhagic shock.

In this cohort of polytrauma patients, many patients also sustained TBI (AIShead $3(1-4)$ ). TBI was also the main cause of death in this population (72\%). Data even suggest that prehospital TXA was often given in patients with TBI since patients who received prehospital TXA had higher AIShead, were more often prehospitally intubated and had higher $\mathrm{PaCO} 2$ with similar $\mathrm{pH}$ in ED (suggestive for prehospital hypoventilation) than patients who did not receive prehospital TXA. Several studies have reported various effects of TXA on outcome in TBI from depending on brain injury severity and timing of TXA administration [26] to no difference in outcome after prehospital TXA [27], or even a potential harmful effect of prehospital TXA on mortality in severe TBI patients [28]. The effect of TXA on TBI in this polytrauma population was beyond the scope of this paper. Future research will focus on the effect of TXA on TBI.

A few limitations need to be acknowledged: First of all, this was a single-institution study. Further, clinicians who were treating these patients were also the researchers. Another limitation is that no details on comorbidities nor any data on prehospital and in-hospital Glasgow Coma Scale were collected.

In conclusion, TXA patients had similar outcome compared to patients without TXA despite being more severely injured. There was a liberal use of both prehospital and inhospital TXA with large numbers of patients receiving TXA without hypotension. Hemorrhagic shock was indication for prehospital TXA in only half the patients, whereas in-hospital TXA was given based on suspicion of hemorrhagic shock in the vast majority of patients. Caution should be exercised since it can be difficult to select the right patient for TXA especially in severely injured patients who do not show grossly signs of deranged physiology prehospitally or on arrival in ED yet.

\begin{abstract}
Authors' contributions KW and LL have contributed to the conception and design of the study, performed acquisition of data and given final approval of the version to be submitted. KW has done the analysis and interpretation of data and drafted the article. LL has revised it critically for important intellectual content.
\end{abstract}

Funding No funds were received in connection with the presented study.
Availability of data and materials The datasets supporting the conclusions of this article are available upon reasonable request from the corresponding author.

\section{Declarations}

Conflict of Interest The authors declare that they have no conflict of interest.

Ethical Approval The local ethics committee approved this prospective observational study and waived consent (reference number WAG/mb/16/026664).

Open Access This article is licensed under a Creative Commons Attribution 4.0 International License, which permits use, sharing, adaptation, distribution and reproduction in any medium or format, as long as you give appropriate credit to the original author(s) and the source, provide a link to the Creative Commons licence, and indicate if changes were made. The images or other third party material in this article are included in the article's Creative Commons licence, unless indicated otherwise in a credit line to the material. If material is not included in the article's Creative Commons licence and your intended use is not permitted by statutory regulation or exceeds the permitted use, you will need to obtain permission directly from the copyright holder. To view a copy of this licence, visit http://creativecommons. org/licenses/by/4.0/.

\section{References}

1. Gruen RL, Jurkovich GJ, McIntyre LK et al (2006) Patterns of errors contributing to trauma mortality: lessons learned from 2,594 deaths. Ann Surg 244:371-380

2. Evans JA, van Wessem KJ, McDougall D et al (2010) Epidemiology of traumatic deaths: comprehensive population-based assessment. World J Surg 34(1):158-163

3. Spahn DR, Bouillon B, Cerny V et al (2019) The European guideline on management of major bleeding and coagulopathy following trauma. Crit Care 23(1):98. https://doi.org/10.1186/ s13054-019-2347-3 (PMID: 30917843; PMCID: PMC6436241)

4. Ramirez RJ, Spinella PC, Bochicchio GV (2017) Tranexamic acid update in trauma. Crit Care Clin 33(1):85-99. https://doi.org/ 10.1016/j.ccc.2016.08.004 (PMID: 27894501)

5. CRASH-2 Trial Collaborators, Shakur H, Roberts I, Bautista R et al (2010) Effects of tranexamic acid on death, vascular occlusive events, and blood transfusion in trauma patients with significant haemorrhage (CRASH-2): a randomised, placebocontrolled trial. Lancet 376(9734):23-32

6. Valle EJ, Allen CJ, Van Haren RM et al (2014) Do all trauma patients benefit from tranexamic acid? J Trauma Acute Care Surg 76(6):1373-1378

7. Myers SP, Kutcher ME, Rosengart MR et al (2019) Tranexamic acid administration is associated with an increased risk of posttraumatic venous thromboembolism. J Trauma Acute Care Surg 86(1):20-27

8. Richards JE, Fedeles BT, Chow JH et al (2021) Is Tranexamic acid associated with mortality or multiple organ failure following severe injury? Shock 55(1):55-60

9. Moore HB, Moore EE, Huebner BR, Stettler GR, Nunns GR, Einersen PM, Silliman CC, Sauaia A (2017) Tranexamic acid is associated with increased mortality in patients with physiological 
fibrinolysis. J Surg Res 220:438-443. https://doi.org/10.1016/j. jss.2017.04.028

10. Guyette FX, Brown JB, Zenati MS, STAAMP Study Group et al (2020) Tranexamic acid during prehospital transport in patients at risk for hemorrhage after injury: a double-blind, placebo-controlled, randomized clinical trial. JAMA Surg 156(1):11-20. https://doi.org/10.1001/jamasurg.2020.4350 (Epub ahead of print. Erratum in: doi: 10.1001/jamasurg.2020.5809. PMID: 33016996; PMCID: PMC7536625)

11. El-Menyar A, Sathian B, Wahlen BM et al (2020) Prehospital administration of tranexamic acid in trauma patients: A 1:1 matched comparative study from a level 1 trauma center. Am J Emerg Med 38(2):266-271. https://doi.org/10.1016/j.ajem.2019. 04.051 (Epub 2019 Apr 30 PMID: 31060862)

12. Rivas L, Estroff J, Sparks A et al (2021) The incidence of venous thromboembolic events in trauma patients after tranexamic acid administration: an EAST multicenter study. Blood Coagul Fibrinolysis 32(1):37-43

13. Cole E, Davenport R, Willett K et al (2015) Tranexamic acid use in severely injured civilian patients and the effects on outcomes: a prospective cohort study. Ann Surg 261(2):390-394

14. Mitra B, Mazur S, Cameron PA, PATCH-Trauma Study Investigators et al (2014) Tranexamic acid for trauma: filling the "GAP" in evidence. Emerg Med Australas. 26(2):194-197

15. Napolitano LM (2017) Prehospital tranexamic acid: what is the current evidence? Trauma Surg Acute Care Open 2(1):e000056. https://doi.org/10.1136/tsaco-2016-000056 (PMID: 29766078; PMCID: PMC5877891)

16. Gunning AC, Lansink KWW, van Wessem KJP et al (2015) Demographic patterns and outcomes of patients in level-1 trauma centers in three international trauma systems. World J Surg 39(11):2677-2684

17. Dewar DC, Tarrant SM, King KL et al (2013) Changes in the epidemiology and prediction of multiple-organ failure after injury. J Trauma Acute Care Surg 74(3):774-779

18. Dewar DC, White A, Attia J et al (2014) Comparison of postinjury multiple-organ failure scoring systems: Denver versus Sequential Organ Failure Assessment. J Trauma Acute Care Surg 77:624-629

19. Sauaia A, Moore FA, Moore EE (1994) Early predictors of postinjury multiple organ failure. Arch Surg 129:39-45

20. Ranieri VM, Rubenfeld GD, Thompson BT, ARDS Definition Task Force et al (2012) Acute respiratory distress syndrome: the Berlin Definition. JAMA 307(23):2526-2533

21. Gunning AC, Leenen LPH (2014) Applicability of the predictors of the historical trauma score in the present Dutch trauma population: modelling the TRISS predictors. J Trauma Acute Care Surg 77:614-619

22. Van Wessem KJP, Leenen LPH (2018) Reduction in mortality rates of postinjury multiple organ dysfunction syndrome: a shifting paradigm? Prospect Popul-Based Cohort Study Shock 49(1):33-38

23. Heirbek T, Jikaria N, Murray B et al (2021) Unjustified administration in liberal use of tranexamic acid in trauma resuscitation. J Surg Res. 258:125-131. https://doi.org/10.1016/j.jss.2020.08. 045 (Epub 2020 Sep 30 PMID: 33010557)

24. Napolitano LM, Cohen MJ, Cotton BA et al (2013) Tranexamic acid in trauma: how should we use it? J Trauma Acute Care Surg 74(6): 1575-1586

25. van Wessem KJP, Leenen LPH (2017) Thromboelastography does not provide additional information to guide resuscitation in the severely injured. ANZ J Surg. https://doi.org/10.1111/ans. 14357 (Epub ahead of print. PMID: 29266754)

26. CRASH-3 Trial Collaborators (2019) Effects of tranexamic acid on death, disability, vascular occlusive events and other morbidities in patients with acute traumatic brain injury (CRASH-3): a randomised, placebo-controlled trial. Lancet 394:1713-1723

27. Rowell SE, Meier EN, McKnight B, Kannas D, May S, Sheehan K, Bulger EM, Idris AH, Christenson J, Morrison LJ, Frascone RJ, Bosarge PL, Colella MR, Johannigman J, Cotton BA, Callum J, McMullan J, Dries DJ, Tibbs B, Richmond NJ, Weisfeldt ML, Tallon JM, Garrett JS, Zielinski MD, Aufderheide TP, Gandhi RR, Schlamp R, Robinson BRH, Jui J, Klein L, Rizoli S, Gamber M, Fleming M, Hwang J, Vincent LE, Williams C, Hendrickson A, Simonson R, Klotz P, Sopko G, Witham W, Ferrara M, Schreiber MA (2020) Effect of out-of-hospital tranexamic acid vs placebo on 6-month functional neurologic outcomes in patients with moderate or severe traumatic brain injury. JAMA 324(10):961-974. https://doi.org/10.1001/jama.2020.8958 (Erratum in: JAMA. 2020 Oct 27;324(16):1683. PMID: 32897344; PMCID: PMC7489866)

28. Bossers SM, Loer SA, Bloemers FW, Den Hartog D, Van Lieshout EMM, Hoogerwerf N, van der Naalt J, Absalom AR, Peerdeman SM, Schwarte LA, Boer C, Schober P (2020) Association between prehospital tranexamic acid administration and outcomes of severe traumatic brain injury. JAMA Neurol. https:// doi.org/10.1001/jamaneurol.2020.4596 (Epub ahead of print. PMID: 33284310)

Publisher's Note Springer Nature remains neutral with regard to jurisdictional claims in published maps and institutional affiliations. 